This item was submitted to Loughborough's Research Repository by the author.

Items in Figshare are protected by copyright, with all rights reserved, unless otherwise indicated.

\title{
Productivity and equity of different irrigation schedules under limited water
} supply

\section{PLEASE CITE THE PUBLISHED VERSION}

\section{PUBLISHER}

(C) American Society of Civil Engineers

\section{LICENCE}

CC BY-NC-ND 4.0

\section{REPOSITORY RECORD}

Smout, lan K., and S.D. Gorantiwar. 2019. "Productivity and Equity of Different Irrigation Schedules Under Limited Water Supply". figshare. https://hdl.handle.net/2134/3662. 
This item was submitted to Loughborough's Institutional Repository by the author and is made available under the following Creative Commons Licence conditions.

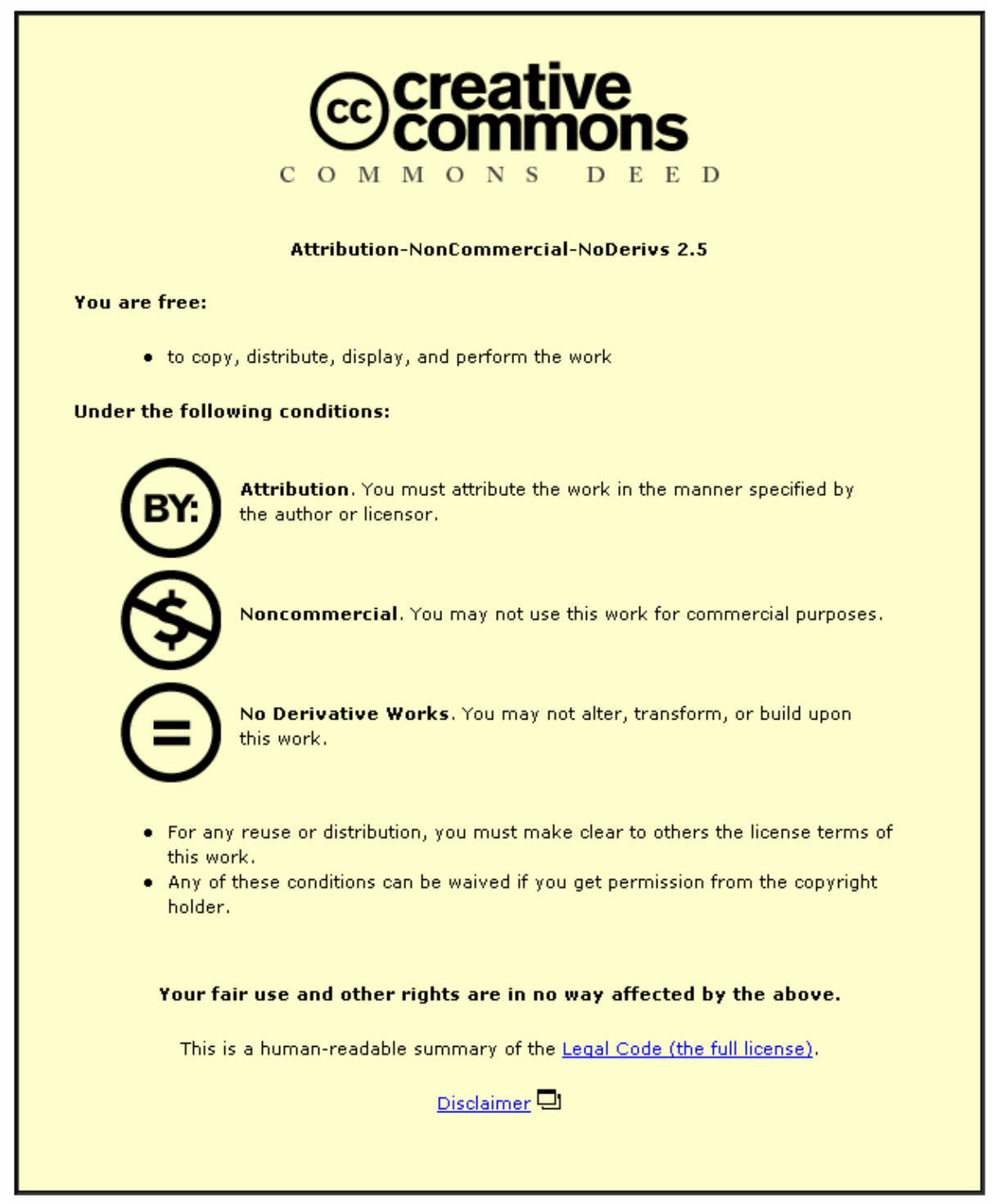

For the full text of this licence, please go to: http://creativecommons.org/licenses/by-nc-nd/2.5/ 


\section{PRODUCTIVITY AND EQUITY OF DIFFERENT IRRIGATION SCHEDULES UNDER LIMITED WATER SUPPLY}

\section{I.K.Smout ${ }^{1}$ and S.D.Gorantiwar ${ }^{2}$}

ABSTRACT: Some irrigation schemes with limited water supply in Central and Southern India follow the area proportionate water distribution based on assumed uniform characteristics of the command area (planned schedule). However in most cases, this planned schedule is overridden by the practice in which users at head draw more than their share of water (actual schedule) due to human factors and technical limitations of the planned schedule. This practice is highly inequitable as users at tail end do not get any water. This paper considers alternative schedules based on full irrigation or deficit irrigation within the framework of area proportionate water distribution in such irrigation schemes and presents the simulation-optimisation technique to develop the corresponding land area and water allocation plan for different allocation units by considering the heterogeneity of the irrigation scheme. This paper further demonstrates the utility of proposed alternative schedules by comparing the productivity and equity of these schedules with planned and actual schedules for one irrigation scheme in Central India. The results show that the actual schedule reduces both productivity and equity greatly and the productivity and equity with the alternative schedules are higher than with the planned schedule. The results also show that deficit irrigation has great potential to increase both productivity and equity of irrigation schemes.

Keywords. Over irrigation, deficit irrigation, water allocation, productivity, equity

\footnotetext{
${ }^{1}$ Director, Water, Engineering and Development Centre, Loughborough University, Leicestershire, LE11 3TU, UK.

${ }^{2}$ Associate Professor, M.P. Agricultural University, Rahuri, India-413 722 and Academic Visitor to Loughborough University, Leicestershire, LE11 3TU, UK.
} 


\section{INTRODUCTION}

Rotational water supply systems locally known as Shejpali or rigid Shejpali are practised for the allocation and distribution of water to farmers in many irrigation schemes of Central and South India. However there is evidence that many times in actual practice, the schedules of these rotational water supply systems are not followed properly, creating a large discrepancy between the planned irrigation schedules and the actual operation. Human factors play a part in this but there are also technical reasons for this discrepancy: firstly the planned schedule assumes that the characteristics of the command area are uniform, and secondly the water supply is limited and unreliable. This paper evaluates the performance of these schedules (planned and actual) in terms of productivity and equity and compares their performance with the schedule based on full irrigation (irrigation to return soil moisture in root zone to field capacity). The paper also considers the schedule based on deficit irrigation (deliberate application of less water than required for full irrigation) (English and Nuss, 1982 and Gorantiwar and Smout, 2003) for improving the performance of irrigation scheme and compares this schedule with the other schedules.

Planned schedule: The planned schedule is based on the demand based Shejpali system where irrigation authorities arrange the supply of water according to the demand of each user in the irrigation scheme within certain constraints (Mandavia, 1998). In this system the irrigation authorities allocate available water to different users on the basis of the area of different crops they propose to cultivate. The irrigation authorities estimate the demands of water for each user to meet the estimated crop water requirement for these areas. However they assume uniform characteristics of the command area and do not 
consider the variation of water requirements with crops and their growth stages while estimating these demands. They then make proportionate reductions in the demand or irrigated area proposed by the users if the total demand is higher than the water available for irrigation, which is usually the case. A schedule, fixing the order or sequence of turns to different users for their sanctioned crop area for irrigation is prepared for each irrigation rotation by following tail to head irrigation approach. In actual operation, the users need to decide whether the irrigation is adequate for the crop being irrigated. Once the allocated area under different crops is irrigated during the rotation, the user passes on the supply of water to the next user. With the limited water supply in the scheme and the history of unreliable water delivery schedules, users are not sure about when the next irrigation will be, and they generally over-irrigate rather than adequately irrigate their fields. To overcome this drawback as well as fixing the sequence of irrigation for each user on a tail to head system the irrigation authorities also set the date, time and duration of irrigation for each user. This system is called rigid Shejpali. This is intended to prohibit the users from overdrawing water. However as stated earlier, the schedules are determined without taking into consideration the soil types, crop growth stages, appropriate losses in application, distribution and conveyance processes, the capacity of the water distribution system etc. These schedules are therefore similar to applying the fixed depth of water to all the farms irrespective of crops, their growth stages, soil and location.

Normally in these schemes the users apply for water for all of their cropland or culturable command area (CCA) because of the limited water available from other sources, the low charge rates paid for irrigation water and the higher benefits from irrigated agriculture. Water available in the irrigation scheme is always less than the 
demand for water from the users and therefore as stated earlier, water is allocated to the users after making a proportional reduction to the crop area for which they have demanded water. The resulting planned schedule is therefore based on proportionate water allocation to users, allocating the available water to each user over the entire irrigation scheme proportionate to their total cropland and delivering water estimated on the basis of fixed depth to all crop area.

Actual schedule: In actual practice, the users do not follow the planned schedule and generally over-irrigate. This happens because the planned schedules become unrealistic as these are determined without taking into consideration the soil types, crop growth stages, appropriate losses in application, distribution and conveyance processes, the capacity of the water distribution system etc. Therefore this type of distribution results in inappropriate water allocation which users do not accept as providing their due share of water. Therefore the users tend to apply as much water as possible over their total cropland as and when they get the supply instead of limiting this to the cropland allotted to them for irrigation, and users in the upstream allocation units take advantage of their position. Thus the water distribution actually practised is to over-irrigate total cropland starting from head of each canal and then the next allocation unit downstream (actual schedule). Thus actual practice or schedule differs from the planned schedule in that in planned schedule all the users in irrigation scheme get water proportional to their total cropland or CCA whereas in actual practice users at head of the system adequately or over irrigate their entire CCA and hence users at tail of the system do not get any water.

In this paper the effect of actual practice or schedule is evaluated in terms of the performance of the irrigation scheme such as productivity and equity and compared 
with the planned schedule and proposed alternative schedules. The alternative schedules are described below.

Alternative schedules based on full and deficit irrigation: Applying a fixed depth of irrigation (as envisaged in the planned schedule) or over-irrigation (as actually practised) results in losses of water because the application of water is not according to actual conditions and needs in each field (as described earlier). Hence an alternative scheduling approach of full irrigation (irrigation to fill the root zone to field capacity) at every irrigation is examined within the framework of each allocation unit receiving water in proportion to its CCA (as planned in Shejpali). Full irrigation attempts to minimise the irrigation losses as in this case, the irrigation depths are estimated considering soil, crops and their growth stages.

Most irrigation schemes in the semi arid tropics are characterised by limited water supply. As water is scarce compared to land in the irrigation schemes in central Indian states like Maharashtra, the deficit irrigation approach could be more beneficial than the full irrigation approach (English and Nuss, 1982; Trimmer, 1990; Keller et al., 1992 and Gorantiwar and Smout, 2003). Hence in this paper the scheduling approach of deficit irrigation is also considered for the allocation within the framework of existing water distribution system.

However due to heterogeneity in the soils, crops to be irrigated and weather parameters influencing water demand and supply in these irrigation schemes, it is a complex task to allocate the land and water resources to different crops and to different parts or units of the command area and to schedule the irrigation water deliveries 
according to the objectives of the irrigation scheme by adopting full or deficit irrigation approach within the framework of area proportionate water distribution. This paper describes the methodology to prepare the allocation plans and water delivery schedules considering the complexities in the irrigation scheme and full or deficit irrigation; and compares the results with the schedules of fixed depth irrigation.

\section{METHODOLOGY}

The methodology developed to evaluate different schedules (planned, actual and proposed alternatives) for their performance in terms of productivity and equity is presented in this Section. The methodology consists of allocating the land and water resources to different crops grown on different soils (crop-soil combination) in different allocation units of the command area according to pre-specified allocation and irrigation strategies. The term Allocation unit (AU) is used for the physical division of the irrigation scheme in to smaller units (which may be individual fields, command area of outlets or secondary or tertiary units of irrigation scheme) over which land and water resources are allocated in the schedule. Each unit may include different soils and crops however the climate is assumed to be uniform over a particular AU. Note that, the climatic conditions may vary across different AUs. The parameters for each of the different schedules are explained below.

1. Actual Schedule (S-Act): The available water is allocated to the total cropland of each AU for each irrigation starting from the AUs at the head of the system. Therefore whenever there is limited water and because of over irrigation, the AUs towards the tail of the system may not receive any water and the objective of area proportionate water 
allocation is contravened. Depending on the degree of over irrigation, there can be different forms of actual schedule. The degree of over irrigation $(\psi)$ in this study is defined as the ratio of the depth of irrigation applied to the depth of full irrigation (as defined below). Thus $\psi=1$ indicates full irrigation (i.e. there is no over irrigation) and $\psi=2$ indicates an irrigation with twice the depth of full irrigation. Note that the degree of over irrigation is not applicable to AUs that do not get water (for example AUs at the tail end).

2. Planned Schedule (S-Pln): The allocation of water to different AUs is proportional to the culturable command area of the AU. As stated earlier, as the heterogeneity in the irrigation scheme in terms of soil, crop, efficiency of the system and other parameters influencing the water demand is not considered in the planned schedule, the fixed depth of water is considered to be applied to all the different crops grown in different AUs for each irrigation.

3. Full irrigation (S-FI): Irrigation water is applied to fill the crop root zone to field capacity considering the heterogeneity in the irrigation scheme (full irrigation depth). The full irrigation depth differs from irrigation to irrigation, crop to crop and soil to soil and the conveyance efficiencies of the canal network, the distribution efficiency of different AUs and application efficiency within the farm influence the water required to be delivered from the headwork so that full irrigation is applied at the farm.

4. Deficit irrigation (S-DI): The deficit irrigation is based on the variable depth irrigation approach suggested by Gorantiwar and Smout (1995) and Gorantiwar and Smout (2003). This approach (Approach-2 described by Gorantiwar and Smout (2003)) consists of applying irrigations with different degrees of deficit. The deficit ratio is used to represent degree of deficit and ranges from zero i.e. applying no irrigation water or skipping this irrigation to one i.e. full irrigation during this irrigation. The intermediate 
values of deficit ratios indicate the irrigation depth as a fraction of the full irrigation depth (for example deficit ratio of 0.4 for a particular irrigation indicates that the irrigation depth applied is 0.4 times the full irrigation depth). The deficit ratio may be different for different irrigations. It is obvious that there could be several sets of deficit ratios associated with each crop-soil combination and hence the optimum set needs to be selected for each crop-soil combination. The optimum set of deficit ratios for the particular crop-soil combination of an AU is the set that leads to maximization of output (net benefits) from the irrigation scheme within the physical limitations of the irrigation scheme and constraints on different resources (Gorantiwar and Smout, 2003).

For both the proposed alternative schedules of full and deficit irrigation, the allocation of water to different AUs is proportional to the culturable command area of the AU which is the same as for the planned schedule. This restriction is not applied to the actual schedule and therefore S-Act $(\psi=1)$ and S-FI do not produce the same results.

The methodology consists of estimating the following for different schedules.

1. The simulation of crop yield, water requirement and estimation of net benefits per unit area for each crop cultivated on different soils that exist in each AU according to each irrigation strategy in the different aforementioned schedules. For example, simulations are performed for irrigation strategies of S-Act $(\psi=1)$, S-Act $(\psi=2)$, S-Pln and S-Fl. In case of S-DI, the simulations are performed for several sets of deficit ratios (the optimisation model (see step-2) selects the set of deficit ratios for each crop-soil combination of each AU that gives the optimum output from the whole irrigation scheme). 
2. The allocation of land area and water (for each irrigation) to different crops in each AU from the total water available for irrigation in the scheme according to water allocation criteria specified for different schedules. Note that for S-Pln, SFI and S-DI, optimal allocation (the allocation that maximizes the total output or net benefits from the scheme) of land area and water resources is performed for different AUs whereas for S-Act schedules, the water is allocated to the whole CCA starting from head of the system and moving downstream until all the water has been allocated. After allocation is performed, the total irrigated area, water delivered and net benefits are estimated for each schedule.

3. Estimation of performance parameters such as productivity and equity.

The simulation-optimisation model is described briefly below together with the methodology for using the model to obtain the performance parameters for all the four schedules. For details, the readers are advised to refer to Gorantiwar (1995) and Smout and Gorantiwar (2005).

\section{Simulation Model}

The methodology adopted for simulation of crop yield and net benefits for a particular crop cultivated on a particular type of soil in a particular AU is described in Fig. 1. The effective rainfall (Dastane, 1974), reference crop evapotranspiration and maximum crop evapotranspiration (Allen et al, 1998), root zone depth (Borg and Grimes, 1986 and Gorantiwar, 1995), soil water depletion (Doorenbos and Kassam, 1986) are estimated daily; and actual yields are estimated by using stage wise crop production function (Stewart and Hagan, 1973) that considers the water stress and yield sensitivity factors during each crop growth stage. The actual evapotranspiration is 
estimated by performing a water balance in the layered soil root zone daily (Gorantiwar, 1995).

The model simulates the yields and net benefits for different crops grown on different soils in all the AUs of the irrigation scheme for a specified irrigation strategy and a given set of irrigation interval over the crop season. For the irrigation strategy of fixed depth irrigation (S-Pln), the depth of irrigation for all the irrigations is prespecified and hence known. For full irrigation (S-FI and S-Act with $\psi=1$ ), the depth of irrigation is estimated as the depth required to fill the crop root zone to field capacity. For S-Act with over irrigation $(\psi>1)$, the depth of irrigation is first estimated for full irrigation and then the actual depth of irrigation is computed for the specified degree of over irrigation. In the case of the deficit irrigation (S-DI), the yields and total net benefits are simulated for different sets of deficit ratios generated by following the procedure developed by Gorantiwar (1995) and Gorantiwar and Smout (2003). The depth of irrigation is the deficit ratio times the depth of full irrigation. The procedure used for the simulation model is summarised in Fig. 2.

\section{Optimisation Model}

In the planned and proposed alternative schedules, the objective is to allocate the available land area and water resources to different crops cultivated in different AUs for obtaining maximum net benefits from the irrigation scheme for the specified irrigation and allocation strategies. For the actual schedule, it is necessary to identify the AUs that are irrigated according to the specified overirrigation criteria starting from head of the system. The optimisation model based on linear programming approach described in this section is used for these purposes. Note that for S-Act, the optimisation model does 
not optimise the total net benefits but identifies the specific AUs and their areas that are irrigated from the head of the system from the available water resources. The optimisation model consists of the objective function which is maximisation of total net benefits and different constraints specifying the water availability and demand during different intraseasonal periods, the system limitation in distributing water and the crop area limitation. The decision variables are the areas to be irrigated by different irrigation programmes under different crops cultivated on different soils of AUs. For S-Act, S-Pln and S-FI, there is only one irrigation programme and it corresponds to the irrigation strategy specified in the schedule. For example in S-Act $(\psi=2)$, the irrigation programme corresponds to applying twice as much water as is required to fill the root zone to field capacity for all the irrigations. In S-DI, there are several possible irrigation programmes corresponding to several sets of deficit ratios. The optimisation model selects the optimum irrigation programme and thus optimum set of deficit ratios for each crop cultivated on different soils in different AUs. The objective function and constraints are described in detail by Gorantiwar (1995) and Smout and Gorantiwar (2005). The objective function for maximisation of net benefits and the constraints used for water allocation to different AUs for different schedules are described below in brief.

Objective function

The objective function of maximisation of total net benefits is given by equation (1).

$\operatorname{Max} \quad B=\sum_{i=1}^{I} \sum_{j=1}^{J_{i}} \sum_{k=1}^{K_{i j}} \sum_{l=1}^{L_{i j k}} b_{i j k l} A_{i j k l}$ 
where

$B=$ the total net benefits (currency unit),

$i=$ index for $i^{\text {th }} \mathrm{AU}$,

$j=$ index for $j^{\text {th }}$ soil group in $i^{\text {th }} \mathrm{AU}$,

$k=$ index for $k^{\text {th }}$ crop cultivated on $j^{\text {th }}$ soil in $i^{\text {th }} \mathrm{AU}$,

$l=$ index for $l^{\text {th }}$ irrigation programme (set of deficit ratio) for $k^{\text {th }}$ crop cultivated on $j^{\text {th }}$ soil in $i^{\text {th }} \mathrm{AU}$

$I=$ the total number of AUs,

$J_{i}=$ total number of soil groups in $i^{\text {th }} \mathrm{AU}$,

$K_{i j}=$ total number of crops that can be cultivated on $j^{\text {th }}$ soil group of $i^{\text {th }} \mathrm{AU}$,

$L_{i j k}=$ total number of irrigation programmes (sets of deficit ratios) for $k^{\text {th }}$ crop cultivated on $j^{\text {th }}$ soil group of $i^{\text {th }}$ allocation unit

$A_{i j k l}=$ Area to be allocated (ha) under $k^{\text {th }}$ crop irrigated by $l^{\text {th }}$ irrigation programme, cultivated on $j^{\text {th }}$ soil group of $i^{\text {th }} \mathrm{AU}$ (decision variables).

$b_{i j k l}=$ estimated net benefits (currency unit/ha) from $k^{\text {th }}$ crop irrigated by $l^{\text {th }}$ irrigation programme, grown on $j^{\text {th }}$ soil group of $i^{\text {th }} \mathrm{AU}$

$L=1$ for S-Act, S-Pln and S-FI (variables and their coefficients in objective function and constraints which are estimated from the simulation model corresponds to specified degree of over irrigation for S-Act, specified fixed depth for S-Pln and full irrigation for S-FI).

\section{Constraints}

1. Area constraints: The total area to be irrigated at any instance in any soil group of an AU in the irrigation scheme should not exceed the maximum irrigable area of the soil group of the AU. These constraints are represented by equation (2). 


$$
\sum_{k=1}^{K_{i j}} \sum_{l=1}^{L_{i j k}} A_{i j k l} \leq A U s_{i j} \quad \text { for } \quad j=1, J_{i} \text { and }
$$

where

$A U s_{i j}=$ maximum irrigable area of $j^{\text {th }}$ soil group of $i^{\text {th }}$ allocation unit (ha),

2. The intraseasonal water supply constraints: The total quantity of water to be delivered for irrigation during any intraseasonal period (irrigation period) should not exceed the total quantity of water that can be made available in that irrigation period. These constraints are represented in the following way (equation 3).

$$
\begin{array}{r}
\sum_{i=1}^{I} \sum_{j=1}^{J_{i}} \sum_{k=1}^{K_{i j}} \sum_{l=1}^{L_{i j k}} d_{h i j k l} A_{i j k l} \leq S_{h-1}-S n+F_{h}-E_{h}-O_{h}-P_{h} \\
\text { for } h=1, H
\end{array}
$$

Continuity

$$
\begin{array}{rlrl}
S_{h-1} & =S_{h-2}+F_{h-1}-E_{h-1}-O_{h-1}-P_{h-1}-\sum_{i=1}^{I} \sum_{j=1}^{J_{i}} \sum_{k=1}^{K_{i j}} \sum_{l=1}^{L_{i j k}} d_{h-1, i j k l} A_{i j k l} & & \text { for } h=2, H \\
& =\text { So } & \text { for } \quad h=1
\end{array}
$$

where

$h=$ index for irrigation

$H=$ total number of irrigations

So $=$ initial reservoir storage (at the beginning of irrigation season) (ha-m), 
$S n=$ dead storage capacity of the reservoir or the minimum storage of water that should always be maintained in the reservoir (ha-m),

$S_{h}=$ reservoir storage capacity at the beginning of $h^{\text {th }}$ irrigation period (ha-m)

$d_{h i j k l}=$ the depth of water to be delivered from the headworks during $h^{\text {th }}$ irrigation interval for $i^{\text {th }}$ irrigation programme for $k^{\text {th }}$ crop grown on $j^{\text {th }}$ soil group in $i^{\text {th }}$ allocation unit of the irrigation scheme (ha-m),

$F_{h}=$ the inflow of water into the reservoir which constitutes the river runoff into the reservoir and rainfall over the reservoir during $h^{\text {th }}$ irrigation period (ha-m),

$E_{h}=$ evaporation losses from the reservoir during $h^{\text {th }}$ irrigation period (ha-m),

$P_{h}=$ seepage losses from the reservoir during $h^{\text {th }}$ irrigation period (ha-m),

$O_{h}=$ water to be diverted for other purposes during $h^{\text {th }}$ irrigation period (ha-m).

3. Water allocation constraints: The total water to be allocated to the AU is proportional to the culturable command area of the AU for the schedules based on fixed depth irrigation (S-Pln), full irrigation (S-FL) and deficit irrigation (S-DI). The equation (4) presents the constraints for this requirement.

$$
\sum_{j=1}^{J_{i}} \sum_{k=1}^{K_{i j}} \sum_{l=1}^{L_{i j k}} d_{h i j k l} A_{i j k l}=D_{i} \quad \text { for } i=1, I
$$

where

$D_{i}=$ the total water to be allocated to $i^{\text {th }} \mathrm{AU}$ (ha-m) according to area proportionate water distribution.

4. Area constraints for S-Act: In S-Act schedule, as the users at the head end draw water first, the total CCA of the AU near the head of the system gets water according to their 
concept of adequate irrigation (degree of over irrigation), prior to any water to CCA of other AUs. In this case, therefore, the allocation needs to be performed for each AU separately, starting from the AU at the head of the system to the AU at the tail of the system, till no water is available for irrigation in the scheme or intraseasonal water supply constraints (equation 3) are violated. This is done by modifying area constraints (equation 2) during the allocation process such that (i) the area to be allocated to all the AUs for which allocation has been performed is set to the allocated area obtained from previous allocation processes (equation 5), (ii) the area to be allocated to other AUs except the AU for which the allocation is being performed is set to zero (equation 7) and (iii) the area to be allocated to the AU for which allocation is being performed is between the minimum limit (zero) and maximum limit (AUs $\mathrm{sij}_{\mathrm{j}}$ ) (equation 6).

$$
\begin{array}{lrr}
\sum_{k=1}^{K_{i j}} \sum_{l=1}^{L_{i j k}} A_{i j k l}=A U s a_{j i} & \text { for } & j=1, J_{i} \text { and } \\
\sum_{k=1}^{K_{i j}} \sum_{l=1}^{L_{i j k}} A_{i j k l} \leq A U s_{i j} & \text { for } & j=1, \text { Ia }-1 \\
& & \\
\sum_{k=1}^{K_{i j}} \sum_{l=1}^{L_{i j k}} A_{i j k l} \leq 0 & & i=1, \text { Ia } \\
& \text { for } & j=1, J_{i} \text { and } \\
& & \\
& & i=I a+1, I
\end{array}
$$

where

$A U s a_{j i}=$ total area allocated for irrigation to $j^{\text {th }}$ soil group of $i^{\text {th }} \mathrm{AU}$ (ha), $I a=$ total number of allocation units for which allocation is being performed 
The outputs of the optimisation model are the total net benefits, the area and water to be allocated and the net benefits estimated from different crops cultivated on different soils for each AU and the water delivery schedule. This is referred to as the allocation plan. The simulation-optimisation technique described above should be applied for a particular irrigation interval (irrigation interval is uniform over the irrigation season) or a set of irrigation intervals (irrigation intervals vary over the irrigation season but are prespecified) over the irrigation season. However the chosen interval or set may not be optimum when obtaining the allocation plans. Hence the results need to be obtained for different irrigation intervals or sets of irrigation interval to choose the appropriate irrigation interval or set and the corresponding allocation plans.

\section{Comparison parameters}

The allocation plans obtained for different schedules are compared for: monetary productivity, area productivity and equity. The monetary productivity is the ratio of the total net benefits of the schedule for which monetary productivity is estimated to the total net benefits of the schedule which gives maximum total net benefits amongst all the schedules considered for comparison. The area productivity is the ratio of the area allocated for irrigation to the culturable command area of the irrigation scheme. The equity is considered over the entire irrigation year as the area proportionate distribution of water and is computed by modifying the Inter Quartile Ratio (Abernethy, 1986) as the ratio of the average allocation ratio for water allocated to all land in the poorest quarter to the average allocation ratio in the best quarter (Gorantiwar and Smout 2005b) and given by equations (8) to (11). The allocation ratio for water allocated to an $\mathrm{AU}$ is the ratio of the actual proportion of water allocated to 
the AU to the desired allocation proportion to the AU (equation 9). In this study, the desired allocation proportion is estimated by considering CCA of AU as the criterion for achieving equity using equation (10). The actual allocation proportion is computed by equation (11).

$E q=\frac{\overline{R a^{p q}}}{\overline{R a^{b q}}}$

where

$\mathrm{Eq}=$ equity for the irrigation scheme

$\overline{\mathrm{Ra}^{\mathrm{bq}}}=$ average of allocation ratios of the best quarter

$\overline{\mathrm{Ra}^{\mathrm{pq}}}=$ average of allocation ratios of the poorest quarter

$R a_{i}=\frac{\lambda a_{i}}{\lambda d_{i}}$

where

$\mathrm{Ra}_{\mathrm{i}}=$ allocation ratio of $\mathrm{i}^{\text {th }} \mathrm{AU}$

$\lambda \mathrm{a}_{\mathrm{i}}=$ actual allocation proportion for $\mathrm{i}^{\text {th }} \mathrm{AU}$

$\lambda \mathrm{d}_{\mathrm{i}}=$ desired allocation proportion for $\mathrm{i}^{\text {th }} \mathrm{AU}$

$\lambda d_{i}=\frac{T A_{i}}{\sum_{i=1}^{I} T A_{i}}$

where 
$\mathrm{TA}_{\mathrm{i}}=\mathrm{CCA}$ of $\mathrm{i}^{\text {th }} \mathrm{AU}$ in ha $\left(\sum_{j=1}^{J_{i}} A U s_{i j}\right)$

$\lambda a_{i}=\frac{T W_{i}}{\sum_{i=1}^{I} T W_{i}}$

where

$\mathrm{TW}_{\mathrm{i}}=$ water allocated to $\mathrm{i}^{\text {th }}$ allocation unit (ha-m)

$\mathrm{TW}_{\mathrm{i}}=\mathrm{V}_{\mathrm{i}} * \mathrm{IA}_{\mathrm{i}}$

$\mathrm{IA}_{\mathrm{i}}=$ area allocated for irrigation or irrigated of $\mathrm{i}^{\text {th }} \mathrm{AU}\left(\sum_{j=1}^{J_{i}} \sum_{k=1}^{K_{i j}} \sum_{l=1}^{L_{i j k}} A_{i j k l}\right)$

$\mathrm{V}_{\mathrm{i}}=$ Volume of water allocated or delivered to the $\mathrm{i}^{\text {th }} \mathrm{AU}\left(\sum_{j=1}^{J_{i}} \sum_{k=1}^{K_{i j}} \sum_{l=1}^{L_{i j k}} d_{h i j k l} A_{i j k l}\right)$

\section{DETAILS OF CASE STUDY}

The "Nazare Medium Irrigation Scheme” in a semi-arid region of Maharashtra State in India was selected for the purpose of case study. Details of the scheme can be found in Gorantiwar (1995) and Gorantiwar and Smout (2005a). The irrigation season of this scheme starts from the $15^{\text {th }}$ October and ends on $14^{\text {th }}$ October of next year. There are three distinct crop seasons within the irrigation season. These are Rabi (midOctober to February), summer (March to June) and Kharif (July to mid-October). The irrigations during Kharif season are of little interest in this study as the reservoir fills during the Kharif season. Therefore for this scheme in this study, the irrigation season was considered to spread over Rabi and summer crop seasons. 
The gross reservoir capacity and dead storage capacity of the reservoir are 22.313 and $5.684 \mathrm{Mm}^{3}$, respectively. A major canal originates from the headworks. The full supply discharge and length of the major canal are $1.528 \mathrm{~m}^{3} / \mathrm{s}$ and $14.80 \mathrm{Km}$, respectively. The cultural command area (CCA) of the irrigation scheme is 3539 ha. There are 32 allocation units (28 direct outlets and four minors). The command area is characterized with four different types of soils). In the present study as two crop seasons formed the irrigation season, gram, sorghum, onion, wheat (Rabi crops), groundnut and sunflower (summer crops) were considered in the analysis.

The details of climatological data, soil properties, efficiencies (conveyance, distribution and application) can be found in Gorantiwar (1995) and Gorantiwar and Smout (2005a). The other data needed for the simulation model were either locally available or documented by FAO (Doorenbos and Pruitt, 1984; Doorenbos and Kassam, 1986 and Allen et al., 1998) and given by Gorantiwar (1995).

\section{SCHEDULES AND CROPPING DISTRIBUTIONS}

\section{Schedules}

Irrigation interval: A fixed irrigation interval of 21 days during Rabi season and 14 days during the summer season has been proposed for the Nazare Irrigation Scheme (Gorantiwar, 1995 and Gorantiwar and Smout, 2005a) for the existing Shejpali rotation system. Hence the performance results for all the four schedules were obtained for this proposed set of irrigation interval. 
Irrigation and allocation strategies: The irrigation depth of $70 \mathrm{~mm}$ per irrigation was proposed for the Nazare Irrigation Scheme (Gorantiwar, 1995 and Gorantiwar and Smout, 2005a). Hence for S-Pln, the irrigation depth of $70 \mathrm{~mm}$ per irrigation was considered. In case of S-Act, three different degrees of over irrigation were considered. These are based on farmers applying full irrigation or over irrigating (thus with different degree of over irrigation, $\psi)$. These are:

1. Full irrigation, $\psi=1$ (S-Act-1)

2. 1.5 times full irrigation, $\psi=1.5$ (S-Act-1.5)

3. 2 times full irrigation, $\psi=2.0$ (S-Act- 2 )

In case of S-FL, the full irrigation depth was calculated for each crop-soil combination which fills the root zone to field capacity. The optimised deficit irrigation (Gorantiwar and Smout, 2003) was considered in case of S-DI. The deficit ratio $(\phi)$ was varied from 0 to 1 at an interval of 0.1 for each irrigation for deficit irrigation. As stated earlier, for S-Act the water was allocated to the entire CCA of each allocation unit starting from the allocation unit at the head and moving downstream to the next allocation unit and so on down to the tail. All other schedules followed the area proportionate water allocation to each AU as incorporated in Shejpali.

Additionally, the results from the simulation and optimization models were obtained for seven sets of irrigation interval for the alternative schedules of deficit and full irrigation. These were 14 (I-14), 21 (I-21), 28 (I-28) and 35 (I-35) days both in Rabi and summer seasons and 21 in Rabi and 14 in summer (I-21-14), 28 in Rabi and 21 in summer (I-28-21) and 35 in Rabi and 21 in summer (I-35-21). 


\section{Cropping distributions}

The allocation plans were obtained for each of above schedules for two cropping distributions: free cropping and fixed cropping. In the free cropping distribution, the model allocates land and water to the crops giving maximum total net benefits. In case of the fixed cropping distribution, the resources were allocated according to a predefined cropping distribution: gram-36\%, sorghum-29\%, onion-14\% and wheat-21 \% in Rabi and Sunflower -33 \% and groundnut-66\% in summer season. It was assumed that $55 \%$ of water is utilised in Rabi and $45 \%$ water is utilised in summer season on the basis of past records and general cropping pattern in the irrigation scheme.

\section{RESULTS}

The allocation plans were obtained with the help of simulation and optimisation models for the different schedules and cropping distributions. This showed that the maximum net benefits were obtained with the deficit irrigation schedule for an irrigation interval of 14 days for both fixed and free cropping distributions. Therefore the productivity was estimated with reference to the net benefits estimated for deficit irrigation with 14 days irrigation interval. The allocation ratios for each $\mathrm{AU}$, from which the equity was estimated for the different schedules are shown in Fig. 3 for fixed cropping distribution and in Fig. 4 for free cropping distribution. The S-FI and S-DI results have a constant allocation ratio of 1 because the schedules are areaproportionate. S-Pln shows some variation from 1, because it is based on a fixed irrigation depth and assumed homogeneity. 


\section{S-Act (overirrigation)}

The productivity and equity values for S-Act are presented in Fig. 5 and Fig. 6 for fixed cropping and free cropping distributions, respectively. These figures show that both productivities (area and monetary) reduced to half when the degree of over irrigation is doubled. Thus the over irrigation has a marked influence on reducing the productivity. However this study did not consider the possible contribution of return flows to groundwater from over irrigation being reused. The equity is zero with this schedule. This is due to the users at the head of the distribution system getting as much water as they desire in the actual schedule, and the tail end users are left with no water. This is evident from the allocation ratios for S-Act with 1.5 times over irrigation (S-Act1.5) as shown in Fig. 3 and Fig. 4 for fixed and free cropping distributions, respectively. Considering that the farmers on this scheme have been observed to over irrigate the fields by $50 \%$, the S-Act with $\psi=1.5$ is considered for further analysis.

\section{S-Pln (fixed depth irrigation)}

Fig. 5 and Fig. 6 compare monetary and area productivities, and equity for actual and planned schedules for fixed and free cropping distributions.

It is observed from the figures that both monetary and area productivities are slightly more for the actual schedule when farmers irrigate adequately (no overirrigation) than for the planned (fixed depth irrigation) schedule, for both free and fixed cropping distributions. This is because in the planned schedule, the area proportionate water distribution is followed for all AUs as against allocation to the AUs towards the head end in the actual schedule. This makes the planned schedule allocate more resources to less productive AUs, which are towards the tail end (due to higher 
conveyance losses). However equity is zero for the actual schedule and 0.76 for the planned schedule. This is due to the users at the head of the distribution system taking water first according to their desire in the actual schedule. However in the planned schedule, the allocation is area proportionate based on assumed uniform characteristics of the irrigation scheme. Thus the allocation of water in case of actual schedule is inequitable and unsatisfactory compared to the planned distribution. When farmers over irrigate, the productivity values for the actual schedule drastically reduce compared to the planned schedule. Thus with over irrigation as observed in the actual schedule, both productivity and equity are considerably lower than in the planned schedule.

\section{S-FI (full irrigation) and proposed S-DI (deficit irrigation)}

The productivity and equity values for the S-FI (full irrigation) for different irrigation intervals are presented in Fig. 7 and Fig. 8 for fixed cropping and free cropping distributions, respectively. It is seen from Fig. 7 that the maximum monetary productivity is obtained with the irrigation interval of I-21-14 days for fixed cropping distribution. The area productivity increases with irrigation interval up to I-28-21 and after that it is almost same. This indicates that the increase in irrigated area due to the deficit caused by prolonging the irrigation interval to more than 21 days in Rabi season and 14 days in summer season did not bring greater net benefits. The equity is one following the area proportionate allocation at the allocation unit. Fig. 8 shows a similar trend for the free cropping distribution.

The productivity and equity values for the S-DI (deficit irrigation) for different irrigation intervals are presented in Fig. 9 and Fig. 10 for fixed cropping and free cropping distributions, respectively. Fig. 9 and Fig. 10 show that the monetary 
productivity decreases with the irrigation interval and the area productivity is almost constant for all the irrigation intervals. This is due to the greater flexibility in water delivery for smaller irrigation intervals due to skipping of irrigations which are not beneficial. The equity is one following the area proportionate allocation at the allocation unit. There is not much difference in monetary productivity of irrigation intervals of I14, I-21-14 and I-21. In the actual and planned schedules, the irrigation interval of I-2114 days is followed and as seen from the results, in the proposed schedule with full irrigation, the irrigation interval of I-21-14 days was also found suitable. Therefore the irrigation interval of I-21-14 days was selected for the proposed schedule with deficit irrigation for further comparison and analysis.

\section{Comparison}

The productivity and equity for actual schedule, planned schedule, proposed schedules of full irrigation and deficit irrigation for fixed cropping distribution are shown in Fig. 11. This figure indicates that the productivity and equity are highest for the deficit irrigation schedule and those for the actual schedule are lowest. The monetary productivity of the full irrigation and deficit irrigation schedules are $5 \%$ and 45\% more than the planned schedule. The area productivity of the full irrigation schedule is lower than the planned schedule. This is due to the application of less depth of irrigation water in the planned schedule than the full irrigation depth. This has resulted in some deficit irrigation, spreading the available water over a comparatively larger area. However the alternative deficit irrigation schedule has greater area productivity than the planned schedule. 
The equity of both the proposed schedules of full and deficit irrigation is $30 \%$ higher than the equity of the planned schedule. This is because the fixed depth irrigation in the planned schedule assumed uniform characteristics of the command area, in particular the application, distribution and conveyance efficiencies. The inappropriate consideration of the conveyance efficiency allocates less water to the users towards the tail end (Fig. 3). A similar trend was observed for the free cropping distribution (Fig. 12 and Fig. 4).

Thus the deficit irrigation schedule is beneficial over full irrigation or the planned schedule of fixed depth irrigation and can be adopted within the framework of the existing system of area proportionate water distribution to allocation units.

\section{SUMMARY AND CONCLUSIONS}

The irrigation schemes in semi arid regions of India have limited water supply and the irrigation authorities follow an area proportionate approach to plan water distribution amongst the different users in these irrigation schemes. In the absence of appropriate allocation plans and schedules however, it is likely that the area proportionate water distribution principle will not be followed in practice. This reduces both productivity and equity. Hence there is a need to develop an appropriate allocation plan and corresponding water delivery schedules to achieve the twin objectives of maximising the productivity and equity in irrigation schemes with limited water supply. This paper shows that these twin objectives can be met by considering the complexity in the irrigation scheme and by deficit irrigation schedules with area proportionate water distribution to each allocation unit. The simulation-optimisation technique is presented 
in this paper for developing allocation plans and schedules based on this approach. This would be useful for the improving the operational performance of irrigation schemes.

This is confirmed by the case study of applying the simulation-optimisation technique on one of the irrigation schemes in the State of Maharashtra, India. This case study demonstrated that the productivity and equity are considerably reduced if the planned area proportionate water allocation (based on fixed depth irrigation assuming uniform conditions in the irrigation scheme) is replaced in practice by over-irrigation and the users at head drawing water first, as is usually the case. The productivity and equity were higher with proposed schedule of deficit irrigation than with with full irrigation schedule and planned fixed depth schedule.

Hence scheduling based on optimal deficit irrigation with the area proportionate water distribution is advisable to enhance both productivity and equity. In this way irrigation authorities can allocate and distribute the limited water available within irrigation schemes in semi arid regions to meet both productivity and equity objectives of the schemes. 


\section{APPENDIX I REFERENCES}

Abernethy, C. L. (1986). "Performance measurement in canal water management: A discussion.” ODI-IIMI Irrigation Management Network, 86/2d, 1-25.

Allen, R.G., Pereira, L.S., Raes, D. and Smith, M. (1998). “Crop evapotranspiration. Guide-lines for predicting crop water requirements.” Food and Agric. Org. Irrig. And Drain. Paper 56, United Nations, Rome, Italy.

Borg, H. and Grimes, D.W. (1986). "Depth development of roots with time: an empirical description.”, Trans. ASAE, 29:194-197.

Dastane, N.G. (1974). “Effective Rainfall.” Food and Agric. Org. Irrig. And Drain. Paper 25, United Nations, Rome, Italy.

Doorenbos, J. and Kassam, A. H. (1986). "Yield response to water.” Food and Agric. Org. Irrig. And Drain. Paper 33, United Nations, Rome, Italy.

Doorenbos, J. and Pruitt, W. O. (1984). "Guide-lines for predicting crop water requirements.” Food and Agric. Org. Irrig. And Drain. Paper 24, United Nations, Rome, Italy.

English, M. and Nuss, G. S. (1982). “Designing for deficit irrigation.” J. Irrig. and Drain. Engrg., ASCE, 108(IR2), 91-106.

Gorantiwar, S. D. (1995). “A model for planning and operation of heterogeneous irrigation schemes in semi-arid regions under rotational water supply” $A P h . D$. Thesis, Loughborough University of Technology, Loughborough, Leicestershire, UK.

Gorantiwar, S.D. and Smout, I.K. (1995). “Optimizing the use of water in a multicropsoil irrigation scheme." Proceedings of the XXVI ${ }^{\text {th }}$ Congress of the International 
Association for Hydraulic Research held at Institution of Civil Engineers, London during 11-15 Sept.,1995. 4:386-391.

Gorantiwar, S.D. and Smout, I.K. (2003). “Allocation of Scarce Water Resources Using Deficit Irrigation in Rotational Systems.” J. Irrig. and Drain. Engrg., ASCE, 129(3): 155-163.

Gorantiwar, S.D. and Smout, I.K. (2005a). “A multilevel approach for optimizing land and water resources and irrigation deliveries for tertiary units in large irrigation schemes: 2. Application.” J. Irrig. and Drain. Engrg., ASCE: 264-272.

Gorantiwar, S.D. and Smout, I.K. (2005b). "Performance assessment of irrigation water management of heterogeneous irrigation schemes: 1. A framework for evaluation.” Irrigation and Drainage Systems, 19:1-36.

Keller, J., Sivanappan, R. K. and.Varadan, K. M. (1992). “Design logic for deficit drip irrigation of coconut trees.” Irrigation and Drainage Systems, 6, 1-7.

Mandavia A.B. (1998). “Modernization of irrigation system operational management by way of canal automation in India.” Modernisation of irrigation system operations: Proceedings of the 5th ITIS network international meeting, Aurangabad, India.

Smout, I.K. and Gorantiwar,S.D. (2005). “A multilevel approach for optimizing land and water resources and irrigation deliveries for tertiary units in large irrigation schemes: 1.Method.” J. Irrig. and Drain. Engrg., ASCE: 254-263.

Stewart, J.I. and Hagan, R.M. (1973). "Functions to predict effects of crop water deficits.” J. Irrig. and Drain. Engrg., ASCE, 99(IR4):421-439.

Trimmer, W. L. (1990). “Applying partial irrigation in Pakistan.” J. Irrig. and Drain. Engrg., ASCE, 116(3), 342-353. 
Captions of figures (figures are arranged in order)

Fig. 1. Simulation of crop yield and net benefits

Fig. 2. Simulation of crop yield and net benefits for different irrigation schedules.

Fig. 3. Allocation ratios for different allocation units for fixed cropping

distribution

Fig. 4. Allocation ratios for different allocation units for free cropping distribution

Fig. 5. Productivity and equity for planned and actual schedules for fixed cropping distribution

Fig. 6. Productivity and equity for planned and actual schedules for free cropping distribution

Fig. 7. The productivity and equity for full irrigation (S-FI) schedule for fixed cropping distribution

Fig. 8. The productivity and equity for full irrigation (S-FI) schedule for free cropping distribution

Fig. 9. The productivity and equity for deficit irrigation (S-DI) schedule for fixed cropping distribution

Fig. 10. The productivity and equity for deficit irrigation (S-DI) schedule for free cropping distribution

Fig. 11. The productivity and equity for different schedules for fixed cropping distribution

Fig. 12. The productivity and equity for different schedules for free cropping distribution 


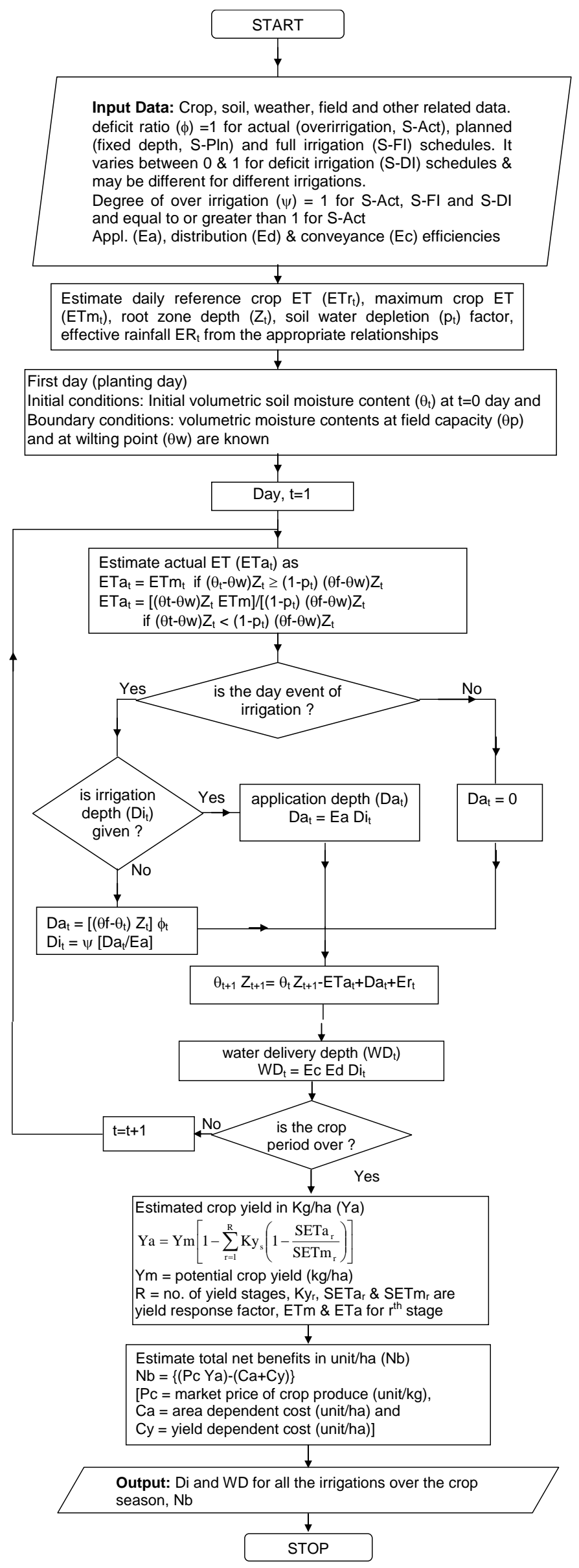




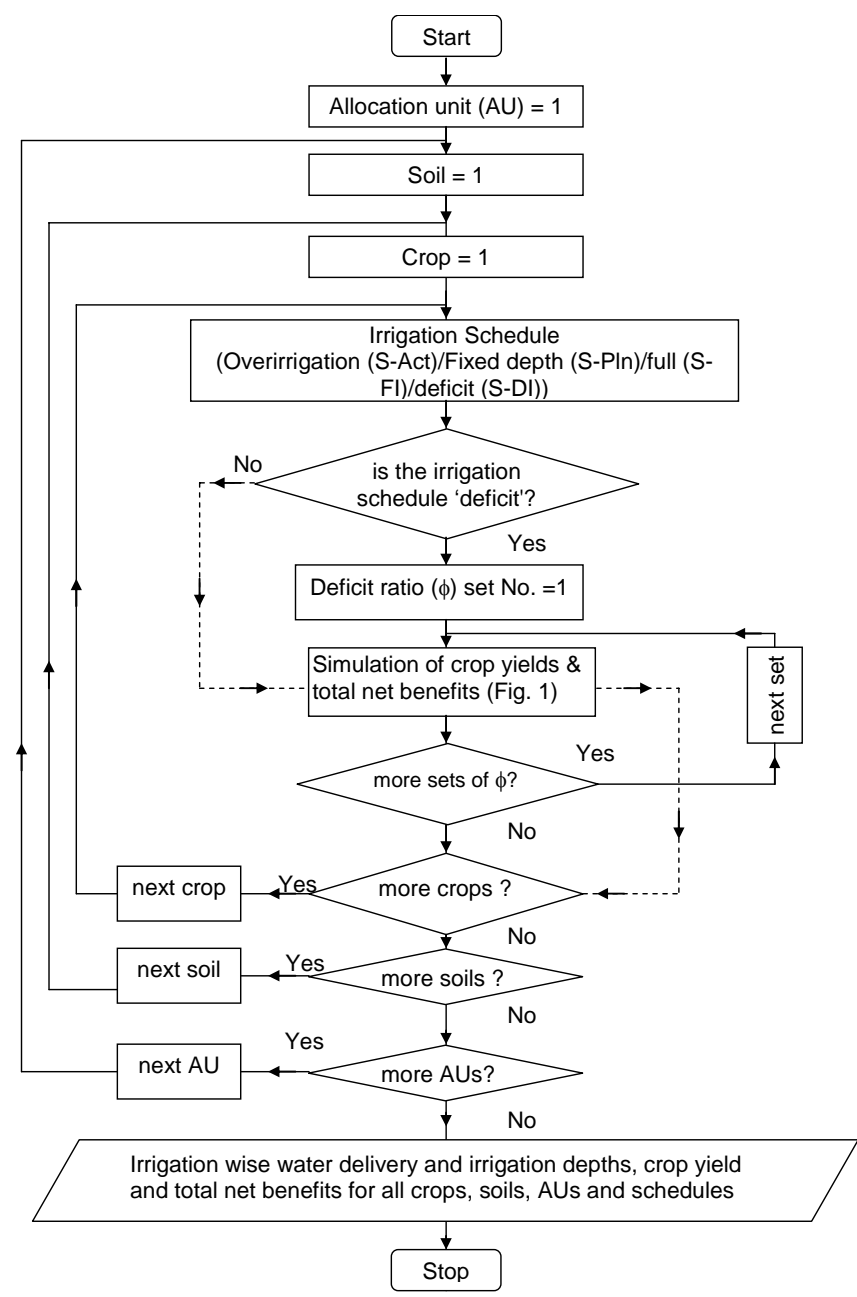




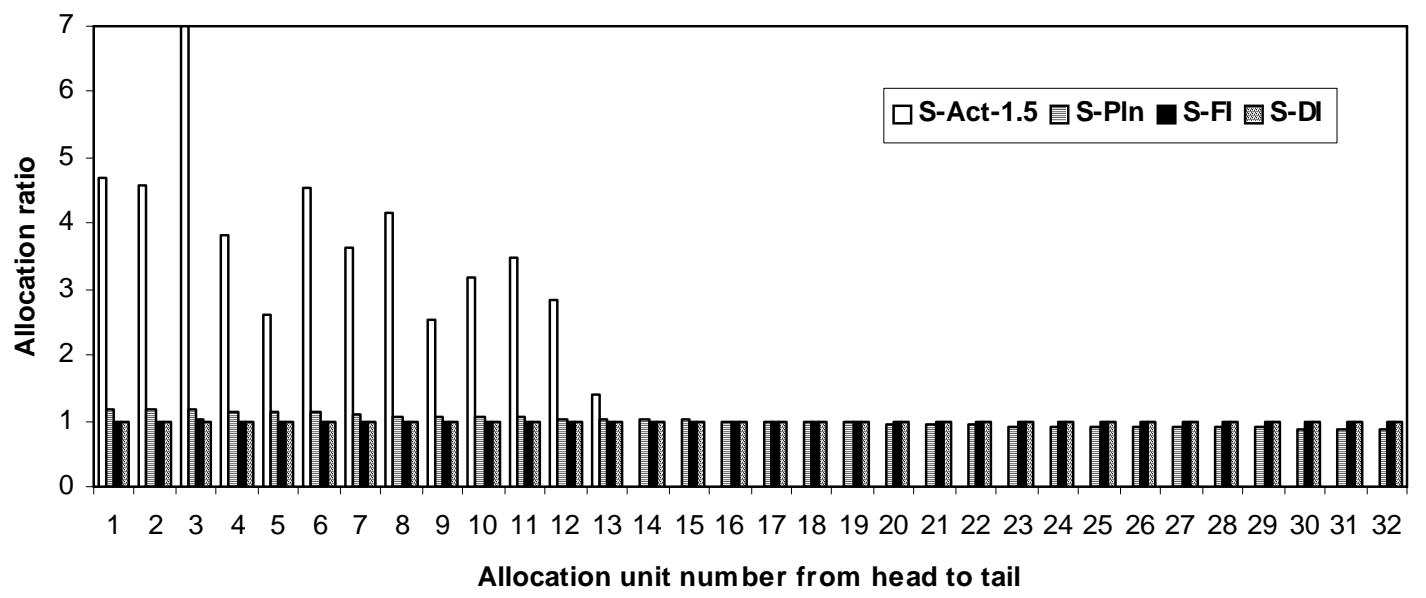

32 


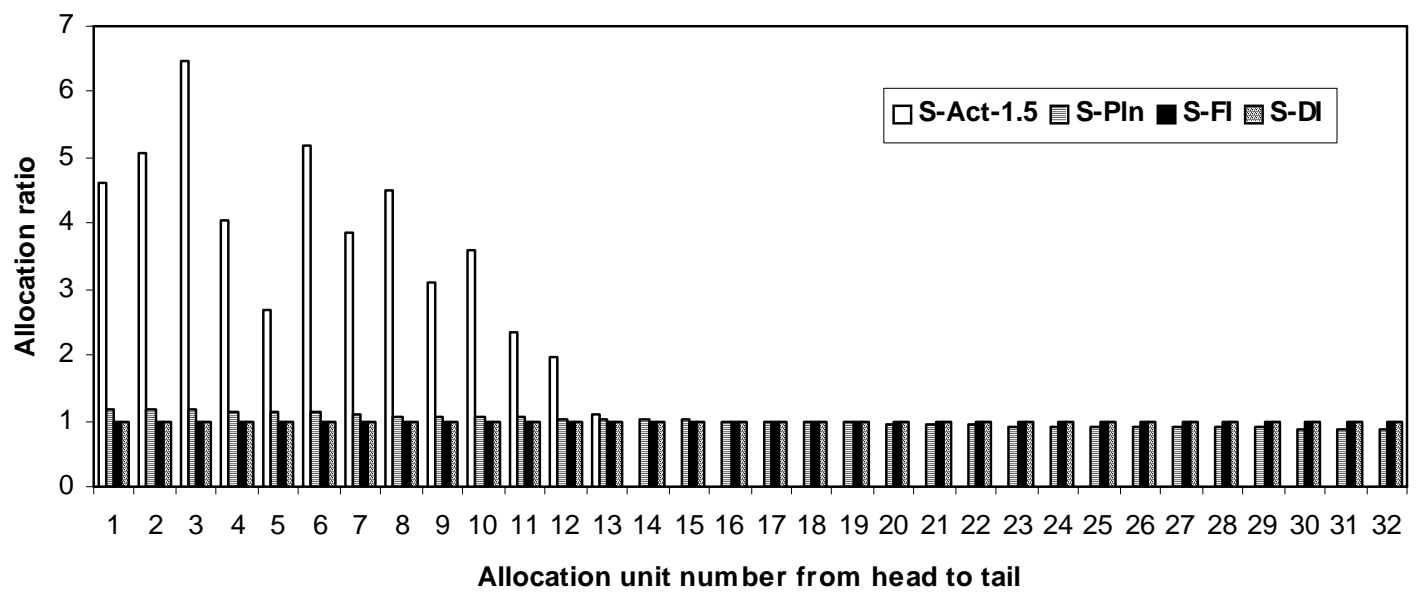

33 


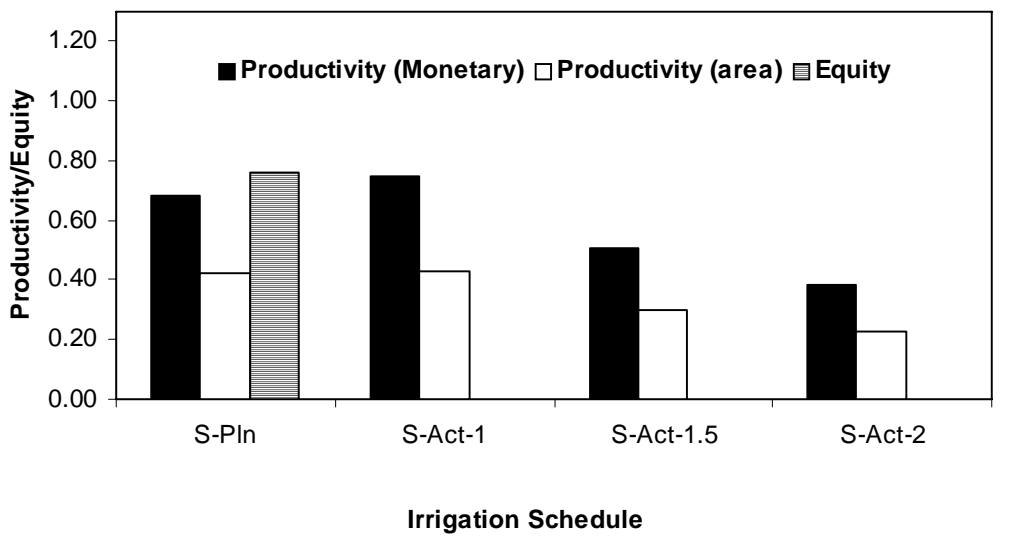

(equity values are zero for S-Act-1, S-Act-1.5 and S-Act-2) 


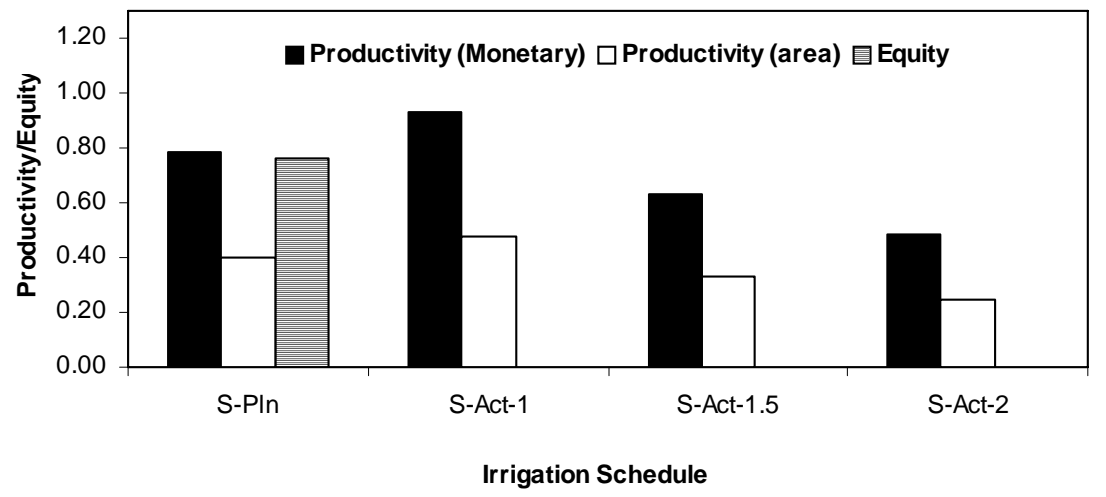

(equity values are zero for S-Act-1, S-Act-1.5 and S-Act-2) 


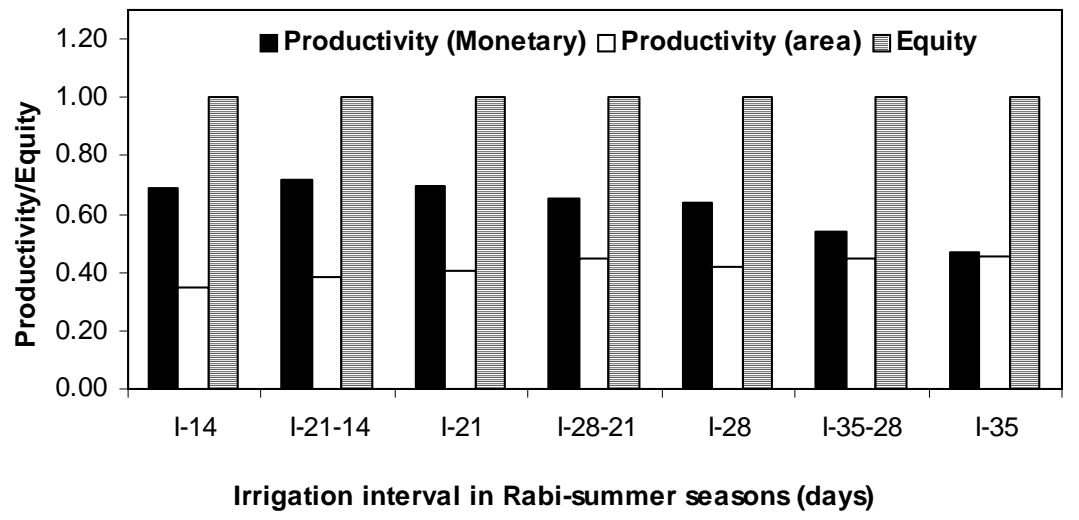




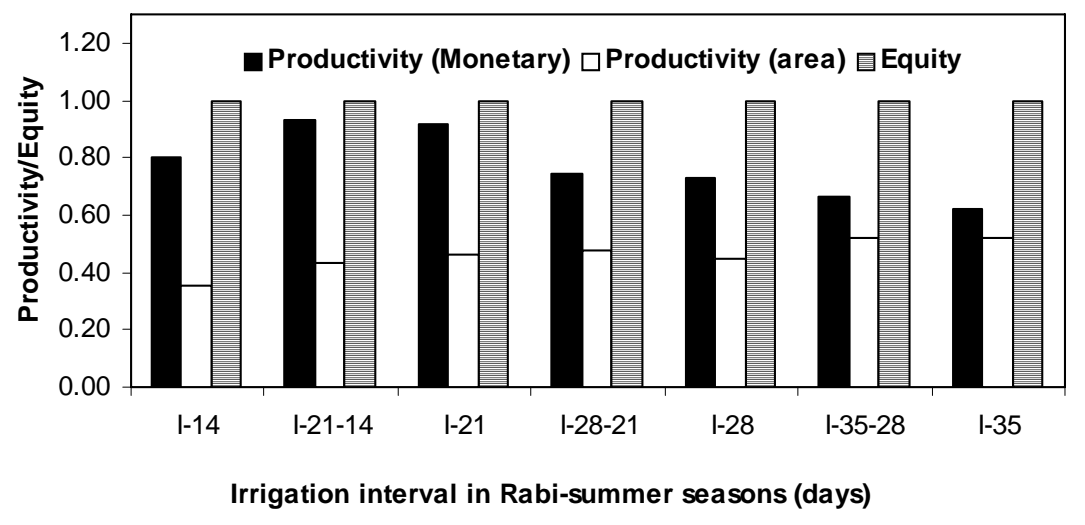




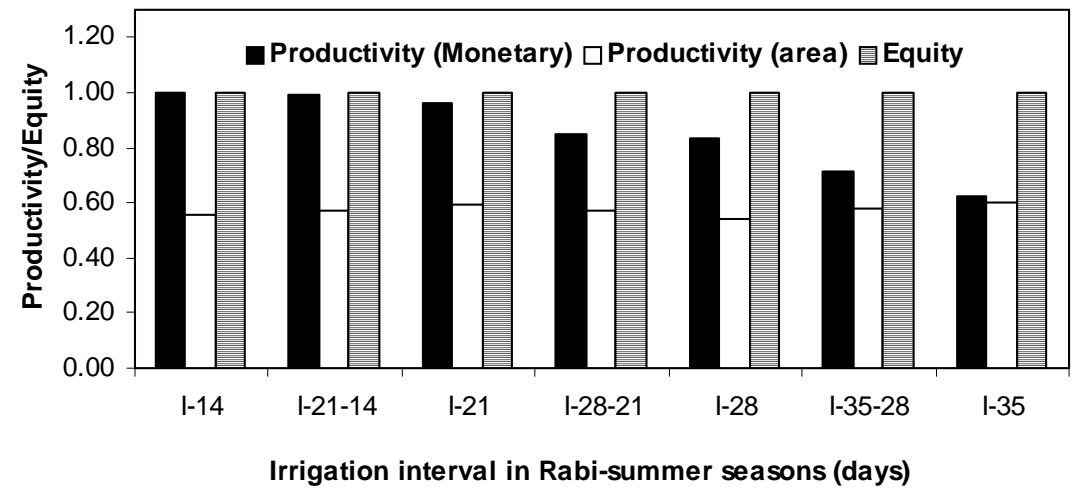




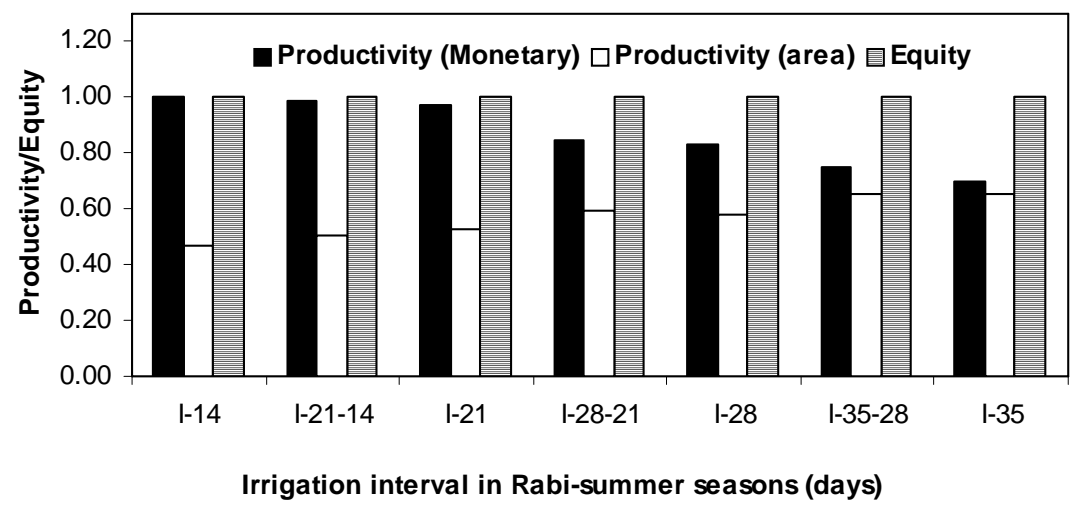




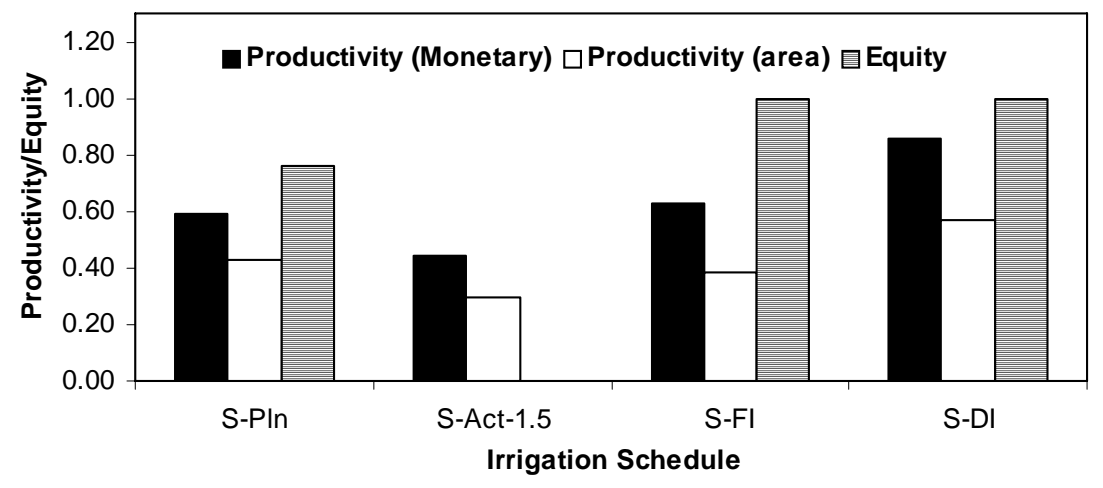

(equity is zero for S-Act-1.5) 


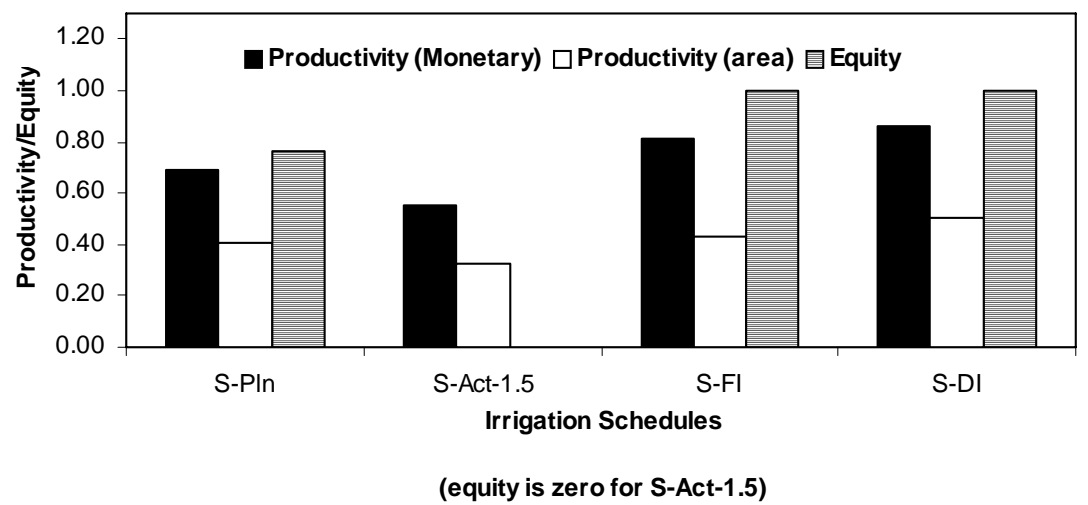

